\title{
Article \\ Chemical and Biological Profiles of Dendrobium in Two Different Species, Their Hybrid, and Gamma-Irradiated Mutant Lines of the Hybrid Based on LC-QToF MS and Cytotoxicity Analysis
}

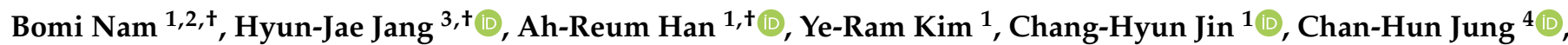

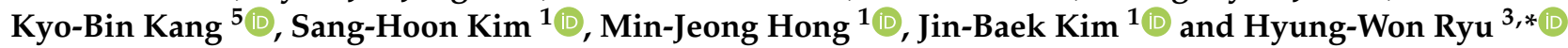 \\ 1 Advanced Radiation Technology Institute, Korea Atomic Energy Research Institute (KAERI), \\ Jeongeup-si 56212, Jeollabuk-do, Korea; bomi1201@ncn.re.kr (B.N.); arhan@kaeri.re.kr (A.-R.H.); \\ yrkim327@kaeri.re.kr (Y.-R.K.); chjin@kaeri.re.kr (C.-H.J.); shkim80@kaeri.re.kr (S.-H.K.); \\ hongmj@kaeri.re.kr (M.J.H.); jbkim74@kaeri.re.kr (J.-B.K.) \\ 2 Institute of Natural Cosmetic Industry for Namwon, Namwon-si 55801, Jeollabuk-do, Korea \\ 3 Natural Medicine Research Center, Korea Research Institute of Bioscience \& Biotechnology (KRIBB), \\ Cheongju-si 28116, Chungbuk-do, Korea; water815@kribb.re.kr \\ 4 Jeonju AgroBio-Materials Institute, Jeonju-si 54810, Jeollabuk-do, Korea; chjung@jami.re.kr \\ check for \\ updates \\ Citation: Nam, B.; Jang, H.-J.; Han, \\ A.-R.; Kim, Y.-R.; Jin, C.-H.; Jung, \\ 5 Research Institute of Pharmaceutical Sciences, College of Pharmacy, Sookmyung Women's University, \\ Seoul 04310, Korea; kbkang@sookmyung.ac.kr \\ * Correspondence: ryuhw@kribb.re.kr; Tel.: +82-43-240-6117 \\ + These authors contributed equally to this work.
} C.-H.; Kang, K.-B.; Kim, S.-H.; Hong, M.-J.; Kim, J.-B.; et al. Chemical and Biological Profiles of Dendrobium in Two Different Species, Their Hybrid, and Gamma-Irradiated Mutant Lines of the Hybrid Based on LC-QToF MS and Cytotoxicity Analysis. Plants 2021, 10, 1376. https://doi.org/ $10.3390 /$ plants10071376

Academic Editors: Igor Jerkovic, Jong Seong Kang and Narendra Singh Yadav

Received: 9 June 2021

Accepted: 1 July 2021

Published: 5 July 2021

Publisher's Note: MDPI stays neutral with regard to jurisdictional claims in published maps and institutional affiliations.

Copyright: (C) 2021 by the authors. Licensee MDPI, Basel, Switzerland. This article is an open access article distributed under the terms and conditions of the Creative Commons Attribution (CC BY) license (https:/ / creativecommons.org/licenses/by/ $4.0 /)$.
Abstract: The Dendrobium species (Orchidaceae) has been cultivated as an ornamental plant as well as used in traditional medicines. In this study, the chemical profiles of Dendrobii Herba, used as herbal medicine, Dendrobium in two different species, their hybrid, and the gamma-irradiated mutant lines of the hybrid, were systematically investigated via ultra-performance liquid chromatography coupled with quadrupole time-of-flight mass spectrometry (UPLC-QToF MS). Among the numerous peaks detected, 17 peaks were unambiguously identified. Gigantol (1), $(1 R, 2 R)-1,7$-hydroxy-2,8-methoxy-2,3dihydrophenanthrene-4(1H)-one (2), tristin (3), (-)-syringaresinol (4), lusianthridin (5), 2,7-dihydroxyphenanthrene-1,4-dione (6), densiflorol B (7), denthyrsinin (8), moscatilin (9), lusianthridin dimer (10), batatasin III (11), ephemeranthol A (12), thunalbene (13), dehydroorchinol (14), dendrobine (15), shihunine (16), and 1,5,7-trimethoxy-2-phenanthrenol (17), were detected in Dendrobii Herba, while 1, 2, and 16 were detected in D. candidum, 1, 11, and 16 in D. nobile, and 1, 2, and 16 in the hybrid, D. nobile $\times$ candidum. The methanol extract taken of them was also examined for cytotoxicity against $\mathrm{FaDu}$ human hypopharynx squamous carcinoma cells, where Dendrobii Herba showed the greatest cytotoxicity. In the untargeted metabolite analysis of 436 mutant lines of the hybrid, using UPLC-QToF MS and cytotoxicity measurements combined with multivariate analysis, two tentative flavonoids (M1 and M2) were evaluated as key markers among the analyzed metabolites, contributing to the distinction between active and inactive mutant lines.

Keywords: Dendrobium; Orchidaceae; D. nobile; D. candidum; D. nobile $\times$ candidum; gamma-irradiated mutant; metabolomics; cytotoxicity

\section{Introduction}

Dendrobium is a genus of mostly epiphytic and lithophytic orchids in the family Orchidaceae [1]. It is a very large genus, containing more than 1800 species that are found in diverse habitats throughout much of South, East, and Southeast Asia, and in many of the islands of the Pacific [1]. The genera with medicinal importance include D. nobile, D. chrysanthum, D. officinale, D. loddigessi, D. fimbriatum var. oculatum, D. moniliforme, and D. candidum $[1,2]$. These have been used as traditional folk remedies for the treatment 
of various diseases, such as chronic atrophic gastritis, diabetes, and cardiovascular disease [3]. Previous phytochemical studies on the Dendrobium species have resulted in the isolation of diverse types of compounds, such as alkaloids [4-10], bibenzyls [9,11-19], phenanthrenes [19-31], fluorenones [18,31], sesquiterpenoids [6,32,33], lignans [21,34], flavonoids [35,36], and polysaccharides [37-39]. These compounds have been reported as exhibiting neuroprotective [4,5], anticancer [6,10-17,25-27,34], antioxidant [18,21,32,36-38], anti-inflammatory [22,23,38], and immunomodulatory activities [39]. In particular, there have been many reports on the mechanisms of their anticancer actions, including apoptosis and cell migration [11-17].

In our previous study, nine phenanthrenes, three bibenzyls, and a lignan were isolated from the ethyl acetate fraction of Dendrobii Herba, which were examined for their cytotoxicity against $\mathrm{FaDu}$ human hypopharynx squamous carcinoma cells [40]. Among them, densiflorol B, 6,7-dimethoxyphenanthrene-2,5-diol, dehydroorchinol, 1,5,7trimethoxy-2-phenanthrenol, ephemeranthol A, and 3-[(1E)-2-(3-hydroxyphenyl)ethenyl]-5methoxyphenol exhibited cytotoxicity, and together with moscatilin, exhibited remarkable activity $\left(\mathrm{IC}_{50}, 2.55 \mu \mathrm{g} / \mathrm{mL}\right)$. In this study, electrospray ionization and the quadrupole time-of-flight mass spectrometry (ESI-QToF MS) data of these isolated compounds and five standards were obtained, as well as the composition of the methanol extracts of Dendrobii Herba, D. nobile, D. candidum, and the hybrid D. nobile $\times$ candidum (Figure 1). In addition, the cytotoxicity of these extracts against FaDu cells was evaluated.

(a)

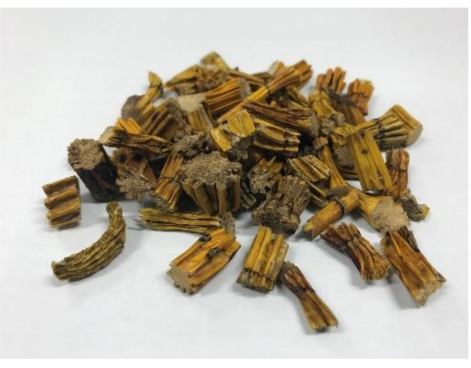

(c)
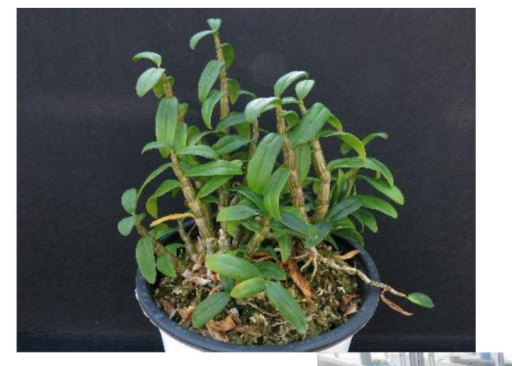

(b)

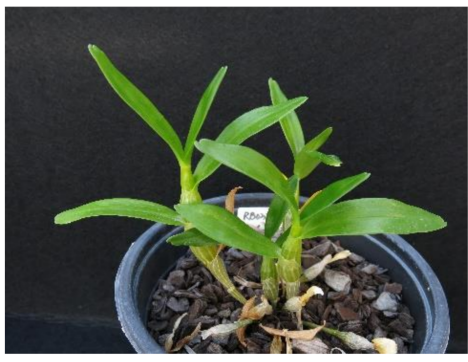

(d)

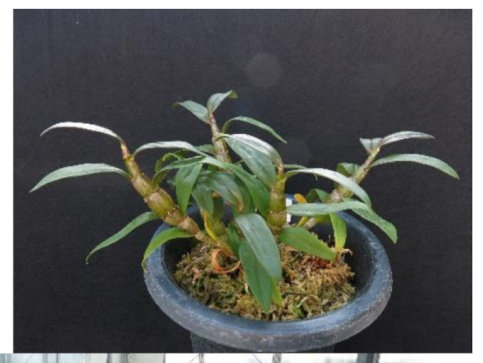

(e)

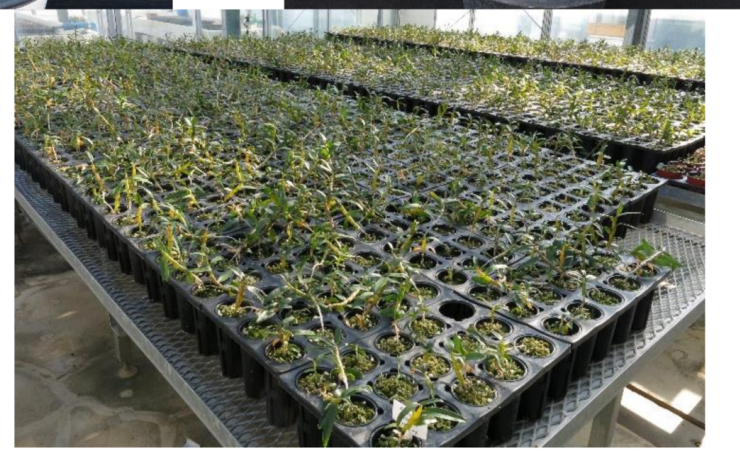

Figure 1. Pictures of the Dendrobium samples, (a) the medicinal herb Dendrobii Herba; (b) D. nobile; (c) D. candidum; (d) the hybrid D. nobile $\times$ candidum; (e) the gamma-irradiated mutant lines of $D$. nobile $\times$ candidum.

Hybridization, genetic modification, or mutation using chemical or physical mutagens to improve the productivity and quality of plants have been widely used in plant breed- 
ing [41,42]. Mutation breeding following gamma irradiation has induced novel mutational traits while preserving the unique properties of the plant [43,44]. Our research group developed mutant lines of the hybrid $D$. nobile $\times$ candidum generated through the gamma irradiation $(20 \mathrm{~Gy})$ of its stems to produce mutants with enhanced biological activities and the improved yield of phytochemicals. Metabolomic studies of the Dendrobium species have previously been reported [45-48], however, there have been no studies on the chemical profile of $D$. candidum, the hybrid, $D$. nobile $\times$ candidum, and its gamma-irradiated mutant lines using LC-MS.

As part of our research project for the development of improved varieties, the chemical compositions of four Dendrobium extracts and their cytotoxicities against FaDu cells were compared, and mutant lines of the hybrid developed by radiation breeding were also evaluated for cytotoxicities with untargeted metabolite analysis. In addition, ultra-performance liquid chromatography coupled with quadrupole time-of-flight mass spectrometry (UPLCQToF MS) and multivariate analysis, including principal component analysis (PCA) and orthogonal partial least squares analysis (OPLS-DA), were applied to characterize the metabolomic differences between the active and inactive mutant lines in FaDu cells.

\section{Results and Discussion}

\subsection{Identification of the Compounds in Dendrobium Samples and Their Cytotoxic Activities}

The compounds 1-17 isolated from Dendrobii Herba [40] were ionized in both negative and positive ion modes using electrospray ionization (ESI). The QToF MS data are listed in Table 1. In addition, LC-MS base peak ion (BPI) chromatograms of all of the compounds and individual high-dimension mass spectra are provided in Figures S1-S17. The UPLC-QToF-MS analysis of the methanol extracts of the stems of four Dendrobium samples (Dendrobii Herba, D. nobile, D. candidum, and the hybrid D. nobile $\times$ candidum) was performed in the negative and positive ion modes (6 eV, ESI). Compared to their ESI ${ }^{-}$ and $\mathrm{ESI}^{+} \mathrm{MS}$ chromatograms, the $\mathrm{ESI}^{-}$of Dendrobii Herba, D. candidum, D. nobile, and $D$. nobile $\times$ candidum provided better sensitivity and lower detection limits compared to the $\mathrm{ESI}^{+}$for the detection of the compounds, as shown in Figure 2. Among the numerous peaks detected, peaks 1-9 and 11-17 were unambiguously identified in Dendrobii Herba by comparing their retention times and masses with the previously acquired data of these compounds. Peak 10 gave a molecular ion at $m / z 481.1639[\mathrm{M}-\mathrm{H}]^{-}$, which is twice the molecular weight of lusianthridin (peak 5) and also exhibited the same fragment pathway as that of peak 5, suggesting that it was tentatively identified as a dimer of lusianthridin. Peak 10 was assumed to be phochinenin G or phochinenin D, as reported in $D$. nobile, because it had the same molecular weight and molecular formula as the lusianthridin dimer [19]. Most of the compounds were hardly detected in D. nobile, D. candidum, and D. nobile $\times$ candidum (Table 2 ). D. nobile contained three peaks: 1,11 , and 16. Specifically, peaks 1,2 , and 16 were detected in D. candidum and D. nobile $\times$ candidum. In previous studies, gigantol (peak 1), moscatilin (peak 9), and dendrobine (peak 15) have been identified in both $D$. nobile $[6,18]$ and $D$. candidum $[49,50]$, whereas densiflorol B (peak 7), denthyrsinin (peak 8), thunalbene (peak 13), (1R,2R)-1,7-hydroxy-2,8-methoxy2,3-dihydrophenanthrene-4(1H)-one (peak 2), and 2,7-dihydroxy-phenanthrene-1,4-dione (peak 6), which were isolated as new compounds in our previous study [40], have never been reported in either plant. Tristin (peak 3), lusianthridin (peak 5), batatasin III (peak 11), ephemeranthol A (peak 12), dehydroorchinol (peak 14), shihunine (peak 16), and 1,5,7-trimethoxy-2-phenanthrenol (peak 17) have been found in D. nobile [19,22,51], but have not been reported in $D$. candidum. The metabolite identification of the hybrid, $D$. nobile $x$ candidum, was reported for the first time in this study. 
Table 1. ESI QToF MS data of compounds isolated from Dendrobii Herba and four standard compounds.

\begin{tabular}{|c|c|c|c|c|c|c|c|}
\hline Peak No. & Identification & $t_{R}(\min )$ & Observed $m / z$ (Da) & $\begin{array}{l}\text { Calculated } \\
m / z \text { (Da) }\end{array}$ & $\begin{array}{l}\text { Error } \\
(\text { ppm) }\end{array}$ & $\begin{array}{l}\text { Molecular } \\
\text { Formula }\end{array}$ & Fragments \\
\hline 1 & $\begin{array}{c}\text { Gigantol } \\
(1 R, 2 R)-1,7-\text { Hydroxy- }\end{array}$ & 1.73 & $275.12688[\mathrm{M}+\mathrm{H}]^{+}$ & 275.1278 & -2.14 & $\mathrm{C}_{16} \mathrm{H}_{18} \mathrm{O}_{4}$ & 198 \\
\hline 2 & $\begin{array}{c}\text { 2,8-methoxy-2,3- } \\
\text { dihydrophenanthrene- } \\
4(1 H) \text {-one }\end{array}$ & 1.98 & $287.09214[\mathrm{M}-\mathrm{H}]^{-}$ & 287.0914 & 4.44 & $\mathrm{C}_{16} \mathrm{H}_{14} \mathrm{O}_{5}$ & 272,239 \\
\hline 3 & Tristin & 2.98 & $259.09822[\mathrm{M}-\mathrm{H}]^{-}$ & 259.0965 & 5.17 & $\mathrm{C}_{15} \mathrm{H}_{16} \mathrm{O}_{4}$ & 243 \\
\hline 4 & (-)-Syringaresinol & 3.32 & $417.15652[\mathrm{M}-\mathrm{H}]^{-}$ & 417.1555 & 5.21 & $\mathrm{C}_{22} \mathrm{H}_{26} \mathrm{O}_{8}$ & 387,190 \\
\hline 5 & $\begin{array}{l}\text { Lusianthridin } \\
\text { 2,7-Dihydroxy- }\end{array}$ & 4.69 & $241.08710[\mathrm{M}-\mathrm{H}]^{-}$ & 241.087 & -4.67 & $\mathrm{C}_{15} \mathrm{H}_{14} \mathrm{O}_{3}$ & 116 \\
\hline 6 & $\begin{array}{l}\text { phenanthrene-1,4- } \\
\text { dione }\end{array}$ & 5.02 & $239.03168[\mathrm{M}-\mathrm{H}]^{-}$ & 239.0339 & -9.26 & $\mathrm{C}_{14} \mathrm{H}_{8} \mathrm{O}_{4}$ & 256 \\
\hline 7 & Densiflorol B & 5.07 & $253.05075[\mathrm{M}-\mathrm{H}]^{-}$ & 253.0495 & 4.11 & $\mathrm{C}_{15} \mathrm{H}_{10} \mathrm{O}_{4}$ & 238 \\
\hline 8 & Denthyrsinin & 5.49 & $299.09974[\mathrm{M}-\mathrm{H}]^{-}$ & 299.0925 & 22.73 & $\mathrm{C}_{17} \mathrm{H}_{16} \mathrm{O}_{5}$ & 284,254 \\
\hline 9 & Moscatilin & 5.63 & $305.13779[\mathrm{M}+\mathrm{H}]^{+}$ & 305.1384 & -3.52 & $\mathrm{C}_{17} \mathrm{H}_{20} \mathrm{O}_{5}$ & 181 \\
\hline 10 & Lusianthridin dimer & 5.84 & $481.16393[\mathrm{M}-\mathrm{H}]^{-}$ & 481.1657 & -4.67 & $\mathrm{C}_{30} \mathrm{H}_{26} \mathrm{O}_{6}$ & 116 \\
\hline 11 & Batatasin III & 6.05 & $243.11115[\mathrm{M}-\mathrm{H}]^{-}$ & 243.1027 & 31.18 & $\mathrm{C}_{15} \mathrm{H}_{16} \mathrm{O}_{3}$ & - \\
\hline 12 & Ephemeranthol A & 6.31 & $273.11093[\mathrm{M}+\mathrm{H}]^{+}$ & 273.1121 & 5.21 & $\mathrm{C}_{16} \mathrm{H}_{16} \mathrm{O}_{4}$ & $272,241,213$ \\
\hline 13 & Thunalbene & 6.43 & $241.08710\left[\mathrm{M}-\mathrm{H}^{-}\right.$ & 241.087 & 1.33 & $\mathrm{C}_{15} \mathrm{H}_{14} \mathrm{O}_{3}$ & - \\
\hline 14 & Dehydroorchinol & 7.7 & $255.10002[\mathrm{M}+\mathrm{H}]^{+}$ & 255.1016 & -2.21 & $\mathrm{C}_{16} \mathrm{H}_{14} \mathrm{O}_{3}$ & 240 \\
\hline 15 & Dendrobine & 7.7 & $264.19496[\mathrm{M}+\mathrm{H}]^{+}$ & 264.1958 & -2.03 & $\mathrm{C}_{16} \mathrm{H}_{25} \mathrm{NO}_{2}$ & - \\
\hline 16 & Shihunine & 7.7 & $203.09751[\mathrm{M}]^{+}$ & 203.0952 & 11.49 & $\mathrm{C}_{12} \mathrm{H}_{13} \mathrm{NO}_{2}$ & 405,203 \\
\hline 17 & $\begin{array}{l}\text { 1,5,7-Trimethoxy-2- } \\
\text { phenanthrenol }\end{array}$ & 7.97 & $285.11172[\mathrm{M}+\mathrm{H}]^{+}$ & 285.1121 & -5.40 & $\mathrm{C}_{17} \mathrm{H}_{16} \mathrm{O}_{4}$ & 253,225 \\
\hline
\end{tabular}

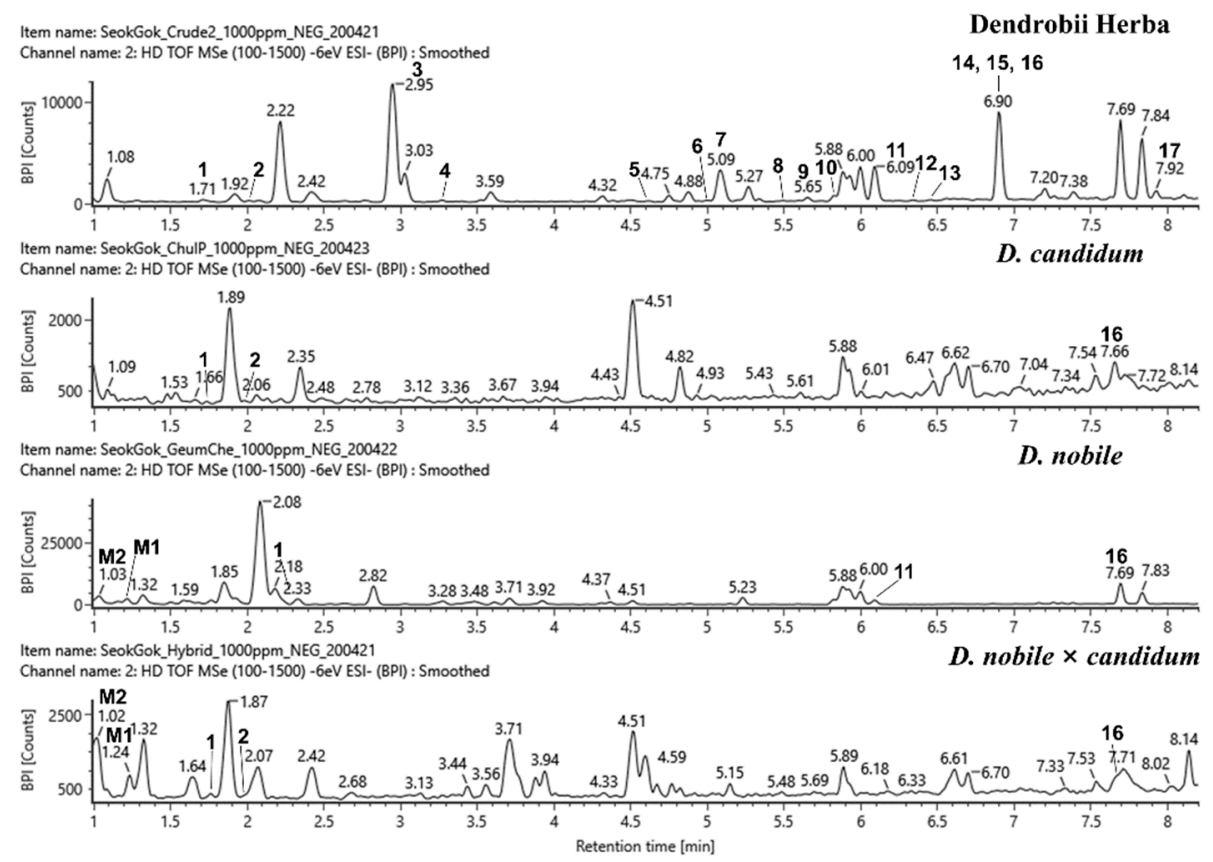

Figure 2. LC-MS base peak ion (BPI) chromatograms of four Dendrobium extracts at negative ion mode $\left(6 \mathrm{eV}, \mathrm{ESI}^{-}\right)$. The selected chromatographic peaks are annotated with peak numbers referred to in Table 2.

In addition, the cytotoxicity of the methanol extracts from four Dendrobium stems against the human pharynx squamous carcinoma $(\mathrm{FaDu})$ cell line was also determined (Table 2 and Figure S20). The methanol extract of Dendrobii Herba showed the greatest activity, with an $\mathrm{IC}_{50}$ value of $63.03 \mu \mathrm{g} / \mathrm{mL}$. The activities of the other Dendrobium samples exhibited $\mathrm{IC}_{50}$ values ranging from 84.47 to $91.93 \mu \mathrm{g} / \mathrm{mL}$, with the hybrid $D$. nobile $\times$ candidum showing the lowest activity. In addition, the methanol extracts of the stems of 436 mutant lines of $D$. nobile $\times$ candidum were prepared and tested for cytotoxic ability against FaDu 
cells at a concentration of $50 \mu \mathrm{g} / \mathrm{mL}$. The samples that showed less than $50 \%$ cell viability were determined as active samples (Table S1).

Table 2. Identification of individual compounds in extracts prepared from Dendrobii Herba, D. nobile, D. candidum, the hybrid, D. nobile $\times$ candidum, and their cytotoxicities against FaDu cells.

\begin{tabular}{|c|c|c|c|c|c|c|c|c|c|c|c|c|c|c|c|c|c|c|}
\hline \multirow{2}{*}{ Samples } & \multirow{2}{*}{$\begin{array}{l}\text { Cytotoxicity }{ }^{1} \\
\left(\mathrm{IC}_{50}, \mu \mathrm{g} / \mathrm{mL}\right)\end{array}$} & \multicolumn{17}{|c|}{ Peak No. } \\
\hline & & 1 & 2 & 3 & 4 & 5 & 6 & 7 & 8 & 9 & 10 & 11 & 12 & 13 & 14 & 15 & 16 & 17 \\
\hline Dendrobii Herba & 63.03 & + & + & + & + & + & + & + & + & + & + & + & + & + & + & + & + & + \\
\hline D. candidum & 84.47 & + & + & - & - & - & - & - & - & - & - & - & - & - & - & - & + & - \\
\hline D. nobile & 89.22 & + & - & - & - & - & - & - & - & - & - & + & - & - & - & - & + & - \\
\hline D. nobile $\times$ candidum & 91.93 & + & + & - & - & - & - & - & - & - & - & - & - & - & - & - & + & - \\
\hline
\end{tabular}

${ }^{1}$ Cisplatin as a positive control showed an $\mathrm{IC}_{50}$ value of $1.52 \mu \mathrm{M}$.

In our previous study of Dendrobii Herba [40], phytochemical investigation on the ethyl acetate-soluble fraction that showed cytotoxicity against $\mathrm{FaDu}$ cells resulted in the isolation of the active compounds, densiflorol B (peak 7), moscatilin (peak 9), ephemeranthol A (peak 12), dehydroorchinol (peak 14), and 1,5,7-trimethoxy-2-phenanthrenol (peak 17). These peaks were only detected in Dendrobii Herba and not in D. nobile, D. candidum, and their hybrid. Therefore, this result suggests that the distribution of the various constituents of Dendrobii Herba contributed more to its potent biological activity than the chemical composition of the other Dendrobium samples. In our further study on the mechanism of action of the most active compound, moscatilin, we have confirmed that moscatilin induced apoptosis in FaDu cells through the extrinsic and intrinsic apoptotic signaling pathways and the c-Jun N-terminal kinase (JNK) signaling pathway [17]. D. nobile constituents have been shown to exert anticancer activities: dendrobine has been shown to enhance the anticancer effect of cisplatin on non-small cell lung cancer cells via JNK stress signaling [10] and to induce apoptosis and inhibit cancer cell invasion in human gastric cells [52]. Nudol has been shown to inhibit the cell proliferation of U2OS osteosacorma cells by inducing cell cycle arrest at the G2/M phase and the migration of U2OS cells, and inducing cell apoptosis through the caspase-dependent pathway [53]. The extract of D. candidum has been reported to decrease the cell viability of human breast cancer cells by inducing cell cycle arrest at the G2/M phase and regulating the biomarkers (ER $\alpha$, PGR, and GATA3) and oncogenes (p53, Ki67, and ELF5) [54]. To the best of our knowledge, the cytotoxicities of the methanol extracts from $D$. nobile, $D$. candidum, and $D$. nobile $\times$ candidum against FaDu cells were reported for the first time.

\subsection{Untargeted UPLC-QToF MS Analysis of Gamma-Irradiated Mutant Lines of D. Nobile $\times$ Candidum}

Recently, multivariate statistical analysis has been shown to be an effective approach in distinguishing differences between experimental setups, in untargeted and targeted metabolomic studies [55]. First, the metabolite profiles of 436 mutant lines grown under the same environmental conditions after $\gamma$-irradiation with the same dose as the stems of $D$. nobile $\times$ candidum were analyzed via UPLC-QToF MS. Second, we performed principal component analysis (PCA), orthogonal partial least squares-discriminant analysis (OPLS-DA), and S-plots, which have been widely used in the field in recent years for the metabolomic analysis of extremely complex samples. There were no significant differences among the mutant lines in the chromatograms (data not shown), however, PCA and OPLS-DA score plots showed a clear separation of the clusters when applying multivariate analysis to the normalized dataset (Figure 3). In particular, supervised OPLS-DA has been widely used to study the differences between two similar groups. The OPLS-DA model quality can be estimated using the cross-validation parameters $Q^{2}$ (model predictability) and $R^{2}(y)$ (total explained variation for the $X$ matrix). OPLS-DA of the samples produced one predictive and one orthogonal $(1+3)$ component and showed that the cross-validated predictive ability $\mathrm{Q}^{2}$ was 0.684 , and the variance related to the differences between the 
two origins $R^{2}(y)$ was 0.693 . In most cases, a $Q^{2}$ value greater than 0.5 is adequate, and the difference between $R^{2}$ and $Q^{2}$ values should be less than 0.3 . Third, the $S$-plot (Point, $t_{R}-m / z$ pair) from the OPLS-DA model, which is a useful tool for comparing the magnitude and reliability of a variable, was also analyzed. The markers associated with the mutant lines of $D$. nobile $\times$ candidum were based on the threshold of variable importance in the projection (VIP) value (VIP > 1.0) from the $S$-plot. The two identified metabolites, M1 and M2, had VIP values greater than 1.0, making them the primary markers of the differences between the two clusters for the mutant lines of $D$. nobile $\times$ candidum on the OPLS-DA score plot (Figure 3).

(a)

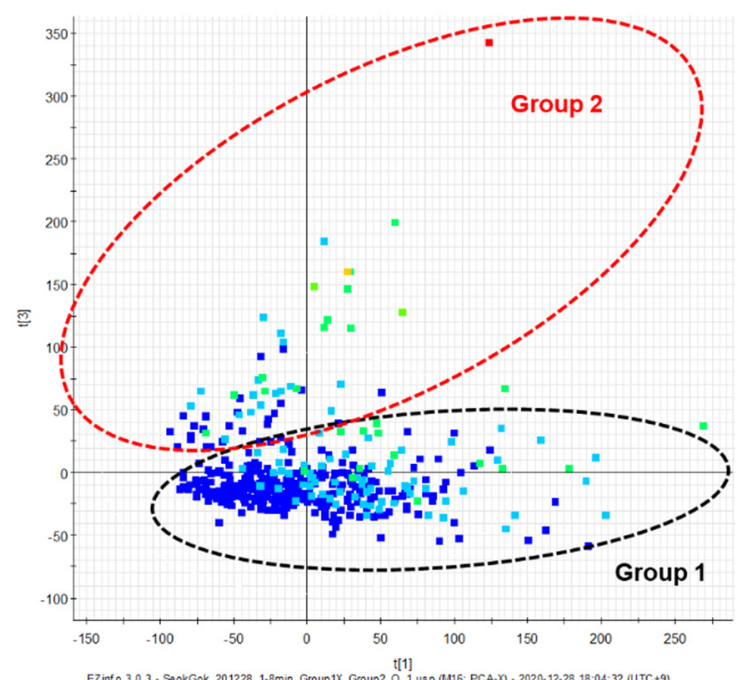

(b)

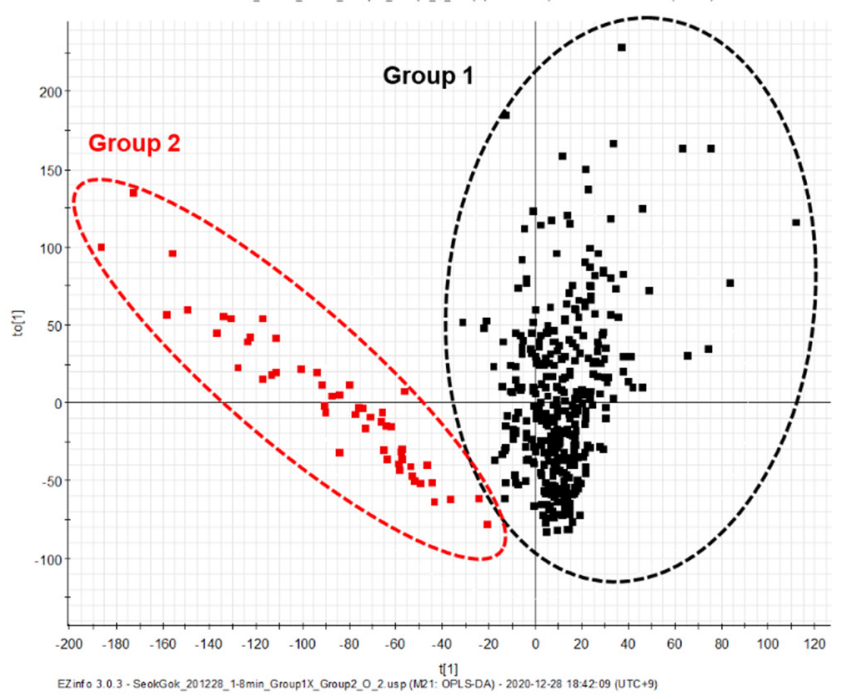

Figure 3. Cont. 
(c)

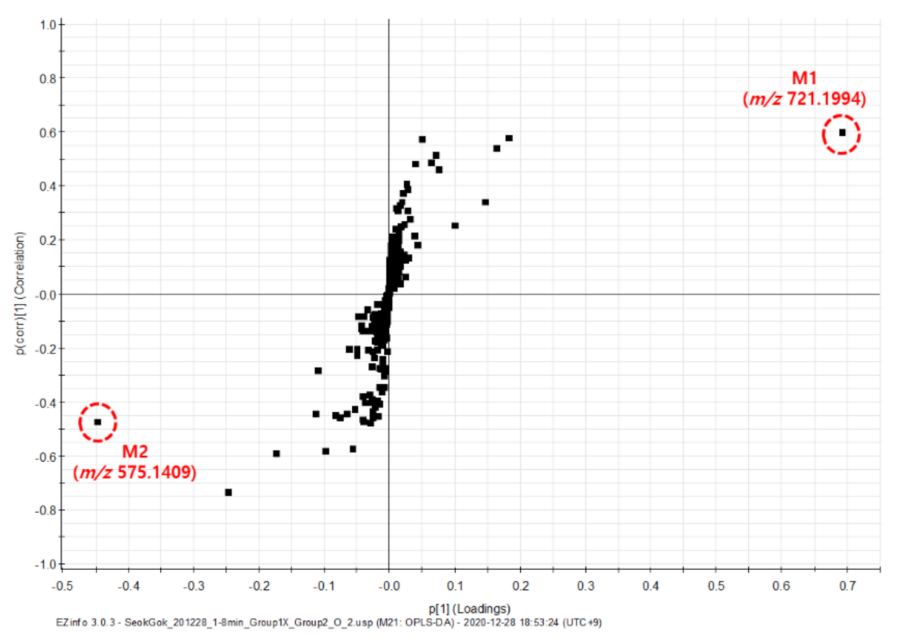

Figure 3. Principal component analysis (PCA) (a) and orthogonal partial least squares-discriminant analysis (OPLS-DA) (b) score plots and (c) S-plots of the inactive and active samples analyzed via UPLC-QToF MS.

Marker ions $\left([\mathrm{M}-\mathrm{H}]^{-}\right)$at $m / z 721.1994$ (M1) were located far from the center and were in the same direction as group 1, indicating distinguishable markers for group 1. Differential markers in the same direction as group 2 demonstrated molecular ions $\left([\mathrm{M}-\mathrm{H}]^{-}\right)$ at $m / z 575.1409$ (M2). These markers were identified as unknown metabolites that did not match with the compounds reported here (1-17) and any compounds previously reported in the Dendrobium species. M1, which belongs to the inactive group, gave a molecular ion at $m / z 721.1994[\mathrm{M}-\mathrm{H}]^{-}$corresponding to the molecular formula $\mathrm{C}_{33} \mathrm{H}_{38} \mathrm{O}_{18}$ and $-0.56 \mathrm{ppm}$ of $\mathrm{m} / \mathrm{z}$ error (Figure S18). The marker M1 $\left(t_{R}=1.03 \mathrm{~min}\right)$ was classified as the 3-hydroxy-3-methylglutaryl (HMG) moiety of $C$-glucoside and C-rhamnoside with MS/MS fragmentation patterns $(m / z 577,487,457,383$, and 353) corresponding to the loss of HMG $(\mathrm{m} / \mathrm{z}$ 144), C-glucoside $(\mathrm{m} / \mathrm{z} 90$ and 120), and C-rhamnoside $(\mathrm{m} / \mathrm{z} 74$ and 104) fragments. Thus, the M1 marker was tentatively identified as apigenin $6-C-\alpha-L-r h a m n o p y r a n o s i d e-8-$

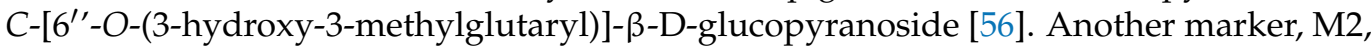
in the active group, demonstrated a molecular ion at $m / z 575.1409\left[\mathrm{M}-\mathrm{H}^{-}\right.$, corresponding to a molecular formula $\mathrm{C}_{27} \mathrm{H}_{28} \mathrm{O}_{14}$ and $-0.38 \mathrm{ppm}$ of $\mathrm{m} / \mathrm{z}$ error (Figure S19). The marker M2 $\left(t_{R}=1.21 \mathrm{~min}\right)$ was classified as the 3-hydroxy-3-methylglutaryl (HMG) moiety and $O$-glucoside with MS/MS fragmentation patterns $(m / z 431$ and 269) corresponding to the loss of the HMG $(m / z ~ 144)$ and O-glucoside $(m / z ~ 162)$ fragments. Thus, the M2 marker was tentatively identified as apigenin 7-O-[6" $-O-(3-h y d r o x y-3-m e t h y l g l u t a r y l)] \beta-$ D-glucopyranoside [57].

Multivariate analysis clearly differentiated the samples into two clusters depending on their activities: a group of 384 extracts without cytotoxicity (Group I) and a group of 52 extracts (Group II) showing less than 50\% cell viability (Figure 3). These results correlated with different metabolites and active components. $\mathrm{C}$-glycosylation or $\mathrm{O}$-glycosylation of apigenin may affect its metabolism, and in turn, affect both its anticancer potential and biological benefits. Previous studies on flavonoids have demonstrated that the sugars of $C$ and/or $\mathrm{O}$-glycosides have potent anticancer properties [58,59]. These results are consistent with those published elsewhere, which also found that these metabolites were the major compounds present in the gamma-irradiated mutant lines of D. nobile $\times$ candidum.

\section{Materials and Methods}

\subsection{General}

UPLC-QToF MS was performed using a Waters ACQUITY UPLC I-Class system combined with a Vion IMS QToF mass spectrometer (Waters, Milford, MA, USA), equipped with an ACQUITY UPLC BEH C18 column $(2.1 \mathrm{~mm} \times 100 \mathrm{~mm}$ i.d., $1.7 \mu \mathrm{m}$; Waters $)$. All 
data were processed using UNIFI software (v1.9, Waters). A $\left({ }^{60} \mathrm{Co}\right)$-irradiator (150 TBq capacity; AECL, Ottawa, ON, Canada) was used for gamma irradiation. Compounds 1-12 were isolated from Dendrobii Herba (the stems of the Dendrobium species), as described in our previous study [40]. The standard compounds, dendrobine (13), batatasin III (16), and lusianthridin (17) were purchased from Wuhan ChemFaces Biochemical Co., Ltd. (Hubei, China). Shihunine (14) and tristin (15) were obtained from Wuhan ChemNorm Biotech Co., Ltd. (Hubei, China) and Chengdu Biopurify Phytochemicals Ltd. (Chengdu, China), respectively. All other chemicals and solvents used in this study were of analytical grade (J. T. Baker, Phillipsburg, NJ, USA).

\subsection{Plant Materials}

Dendrobii Herba stems (CK PHARM Co., Ltd., Seoul, Korea) were purchased from the Jewondang herb shop in Jeongup-si, Jeollabuk-do, Korea. D. nobile, D. candidum, the hybrid $D$. nobile $\times$ candidum, and its gamma-irradiated mutant lines were verified as authentic and grown by Dr. Sang Hoon Kim (Korea Atomic Energy Research Institute). The hybrids (D. nobile $\times$ candidum) were irradiated with a single dose of $\gamma$-rays (20 Gy) emitted from a labeled cobalt $\left({ }^{60} \mathrm{Co}\right)$ source (150 TBq capacity; AECL) for $24 \mathrm{~h}$ at the Korea Atomic Energy Research Institute, Jeongeup-si, Korea. Approximately 1400 gamma-irradiated mutant lines derived from $D$. nobile $\times$ candidum were grown in a greenhouse under the same conditions as D. nobile, D. candidum, and D. nobile $\times$ candidum for two years (2017-2019). Two to three stems of these plant materials with good growth and yield (approximately 400 in total) were randomly collected in November 2019. The collected stems were dried using an air-drying method (air-conditioned at a temperature of $40^{\circ} \mathrm{C}$ for $72 \mathrm{~h}$ ). Voucher specimens of D. nobile (accession no. RB033), D. candidum (accession no. RB030), and the hybrid D. nobile $\times$ candidum (accession no. RB038) were deposited at the Advanced Radiation Technology Institute, Korea Atomic Energy Research Institute.

\subsection{Sample Preparation}

Dried stems of Dendrobii Herba, D. nobile, D. candidum, the hybrid D. nobile $\times$ candidum, and its gamma-irradiated mutant lines were chopped into small pieces. One gram of each stem was extracted with $30 \mathrm{~mL}$ of methanol using an ultrasonic bath for $60 \mathrm{~min}$ and was evaporated to produce the methanol extract. Each dried methanol extract $(1 \mathrm{mg})$ was dissolved in $1 \mathrm{~mL}$ of methanol for UPLC-QTof MS analysis. Compounds 1-17 were dissolved in methanol at a concentration of approximately $0.1 \mathrm{mg} / \mathrm{mL}$. This sample solution was filtered through a $0.20-\mu \mathrm{m}$ polyvinylidene fluoride filter for chromatographic analysis. For cytotoxicity evaluation, each dried methanol extract $(1 \mathrm{mg})$ was initially dissolved in dimethyl sulfoxide at a concentration of $100 \mathrm{mg} / \mathrm{mL}$. Subsequently, the final concentration was diluted to $1.5625,3.125,6.25,12.5,25,50$, and $100 \mu \mathrm{g} / \mathrm{mL}$ using a minimum essential medium (MEM; Corning, Manassas, VA, USA) for Dendrobii Herba, D. nobile, D. candidum, and the hybrid $D$. nobile $\times$ candidum, respectively, and $50 \mu \mathrm{g} / \mathrm{mL}$ for the gamma-irradiated mutant lines of the hybrid.

\subsection{UPLC-QTof MS Analysis}

The methanol extracts of Dendrobii Herba, D. nobile, D. candidum, the hybrid, D. nobile $\times$ candidum, and compounds (1-17) were analyzed using a Waters ACQUITY UPLC I-Class system combined with a Vion IMS QToF mass spectrometer (Waters). Each sample (1000 ppm, $2 \mu \mathrm{L})$ was injected into an ACQUITY UPLC BEH C18 column $(2.1 \mathrm{~mm} \times 100 \mathrm{~mm}$ i.d., $1.7 \mu \mathrm{m}$; Waters). The temperature of the column oven was maintained at $35^{\circ} \mathrm{C}$. The flow rate was $0.4 \mathrm{~mL} / \mathrm{min}$ using a mobile phase comprising $0.1 \%$ formic acid in water $(v / v$; solvent $\mathrm{A})$ and $0.1 \%$ formic acid in acetonitrile $(v / v$; solvent $B)$. Gradient elution was carried out as follows: 0-1.0 min, 23\% B; 1.0-3.0 min, 23-27\% B; 3.0-5.5 min, 27-37\% B; 5.5-8.0 min, 37-62\% B; $8.0-8.3 \mathrm{~min}, 62-100 \% \mathrm{~B} ; 8.3-10.0 \mathrm{~min}, 100 \% \mathrm{~B} ; 10.0-10.3 \mathrm{~min}, 100-23 \% \mathrm{~B} ; 10.3-12.0 \mathrm{~min}, 23 \%$ $B$. The mass spectrometer was operated in negative or positive ion mode with the following parameters: source temperature, $110{ }^{\circ} \mathrm{C}$; desolvation temperature, $350^{\circ} \mathrm{C}$; capillary voltage, 
$2300 \mathrm{~V}$; cone voltage, $40 \mathrm{~V}$; cone gas flow, $50 \mathrm{~L} / \mathrm{h}$; flow rate of desolvation gas $\left(\mathrm{N}_{2}\right), 800 \mathrm{~L} / \mathrm{h}$; mass scan range, 100-1500 Da; scan time, $0.1 \mathrm{~s}$. The full scan data, MS/MS spectra, accurate mass, and elemental composition were calculated using UNIFI software (Waters).

\subsection{Cytotoxicity Assay}

Human pharynx squamous carcinoma FaDu cells were purchased from the Korean Cell Line Bank (Seoul, Korea). These cells were cultured in a minimum essential medium (MEM; Corning, Manassas, VA, USA) supplemented with 10\% heat-inactivated FBS (Hyclone, Logan, UT, USA) in a humidified incubator with $5 \% \mathrm{CO}_{2}$ at $37^{\circ} \mathrm{C}$. To determine the viability of FaDu cells, a CCK-8 assay kit (Dojindo, Kumamoto, Japan) was used according to the manufacturer's protocol. Briefly, FaDu cells were seeded into 96-well plates at a density of $2 \times 10^{4}$ cells $/ \mathrm{mL}$ and incubated at $37^{\circ} \mathrm{C}$ for $24 \mathrm{~h}$. After incubation, the cultured FaDu cells were treated with the indicated concentration of four Dendrobium extracts $(1.5625-100 \mu \mathrm{g} / \mathrm{mL})$ and the extracts of mutant lines $(50 \mu \mathrm{g} / \mathrm{mL})$ for $72 \mathrm{~h}$. Thereafter, $10 \mu \mathrm{L}$ of CCK-8 reagent was added to the cultured FaDu cells and then incubated for a further $4 \mathrm{~h}$, after which the absorbance was measured at $450 \mathrm{~nm}$ using a SPARK ${ }^{\circledR}$ multimode microplate reader (Tecan, Männedorf, Switzerland). Afterward, the $50 \%$ inhibitory concentration $\left(\mathrm{IC}_{50}\right)$ values were calculated from a dose-response analysis performed using GraphPad Prism software (GraphPad Software, La Jolla, CA, USA).

\subsection{Chemometric Data Analysis}

The raw mass data were normalized to the total intensity (area) and analyzed using Progenesis ${ }^{\circledR} \mathrm{QI}$ software v2.4 (Waters). The parameters included a retention time range of 1.0-8.0 min, a mass range from $100 \mathrm{Da}$ to $1,500 \mathrm{Da}$, and a mass tolerance of $0.01 \mathrm{Da}$. The isotopic data were excluded, the noise elimination level was 10, and the mass and retention time windows were $0.04 \mathrm{~min}$ and $0.1 \mathrm{~min}$, respectively. After creating a suitable processing method, the dataset was processed using the Create dataset window. The resulting two-dimensional matrix for the measured mass values and intensities for each sample was further exported to EZinfo software v3.0.3 (Waters) using both unsupervised principal component analysis and supervised OPLS-DA.

\section{Conclusions}

In conclusion, the chemical compositions of Dendrobii Herba, D. nobile, D. chrysanthum, and their hybrid, D. nobile $\times$ candidum, were analyzed via UPLC-QToF MS and were identified by comparing the ESI QToF MS data of the isolates (1-13) from Dendrobii Herba and the standards (14-17). The results showed that the chemical compositions of each sample were different, demonstrating that each sample from different species could be well-distinguished, and the quality of the different samples could be determined through this method. The distribution and content of the constituents of each sample were estimated to be related to their cytotoxic activities against FaDu cells. In addition, UPLC-QToF MS combined with multivariate analysis was used to analyze the chemical profiles of the gamma-irradiated mutant lines derived from $D$. nobile $\times$ candidum. The results showed a clear separation of different groups of the mutant lines and the distinguished marker metabolites (M1 and M2), according to the two clusters. These markers were tentatively identified as apigenin $6-C-\alpha-\mathrm{L}-$ rhamnopyranoside- $8-C-\left[6^{\prime \prime}-O-(3-\right.$ hydroxy-3-methylglutaryl)]- $\beta$-D-glucopyranoside and apigenin 7-O-[6" $-O-(3-h y d r o x y-3-$ methylglutaryl)]- $\beta$-D-glucopyranoside, respectively. Based on the cytotoxicity screening results, the samples were also divided into two groups (384 inactive samples and 52 active samples), where these markers corresponded to the two groups contributing to the correlation of the inactive and active extracts, respectively. This study was an attempt to select superior and differentiated mutant lines based on biochemical analyses. Therefore, these results will serve as a reference for future investigations of the mutation mechanism of the gamma-irradiated mutant lines and their quality evaluation for improved mutant selection. 
Supplementary Materials: The following are available online at https:/ /www.mdpi.com/article/ 10.3390/plants10071376/s1, Figure S1: ESI QTof MS spectrum of gigantol (peak 1), Figure S2: ESI QTof MS spectrum of (1R,2R)-1,7-hydroxy-2,8-methoxy-2,3-dihydrophenanthrene-4(1H)-one (peak 2), Figure S3: ESI QTof MS spectrum of tristin (peak 3), Figure S4: ESI QTof MS spectrum of (-) syringaresinol (peak 4), Figure S5: ESI QTof MS spectrum of lusianthridin (peak 5), Figure S6: ESI QTof MS spectrum of 2,7-dihydroxy-phenanthrene-1,4-dione (peak 6), Figure S7: ESI QTof MS spectrum of densiflorol B (peak 7), Figure S8: ESI QTof MS spectrum of denthyrsinin (peak 8), Figure S9: ESI QTof MS spectrum of moscatilin (peak 9), Figure S10: ESI QTof MS spectrum of lusianthridin dimer (peak 10), Figure S11: ESI QTof MS spectrum of batatasin III (peak 11), Figure S12: ESI QTof MS spectrum of ephemeranthol A (peak 12), Figure S13: ESI QTof MS spectrum of thunalbene (peak 13), Figure S14: ESI QTof MS spectrum of dehydroorchinol (peak 14), Figure S15: ESI QTof MS spectrum of dendrobine (peak 15), Figure S16: ESI QTof MS spectrum of shihunine (peak 16), Figure S17: ESI QTof MS spectrum of 1,5,7-trimethoxy-2-phenanthrenol (peak 17), Figure S18: ESI QTof MS spectrum of differential metabolite (M1), Figure S19: ESI QTof MS spectrum of differential metabolite (M2), Figure S20: Cytotoxicities of the methanol extracts of Dendrobii Herba, D. nobile, D. candidum, the hybrid, D. nobile $\times$ candidum against FaDu cells, Table S1: Cell viabilities of the methanol extracts of the stems of 436 mutant lines of $D$. nobile $\times$ candidum at a concentration of $50 \mu \mathrm{g} / \mathrm{mL}$ in FaDu cells.

Author Contributions: Conceptualization, A.-R.H. and H.-W.R.; methodology, A.-R.H., C.-H.J. (Chang-Hyun Jin), C.-H.J. (Chan-Hun Jung), S.-H.K. and H.-W.R.; software, B.N., H.-J.J., Y.-R.K. and M.-J.H.; validation, A.-R.H., C.-H.J. (Chang-Hyun Jin), K.-B.K. and H.-W.R.; formal analysis, B.N., H.-J.J., Y.-R.K. and C.-H.J. (Chang-Hyun Jin); investigation, B.N., H.-J.J., Y.-R.K., C.-H.J. (Chang-Hyun Jin), K.-B.K. and S.-H.K.; resources, C.-H.J. (Chan-Hun Jung) and S.-H.K.; data curation, B.N., H.-J.J., A.-R.H., K.-B.K. and H.-W.R.; writing-original draft preparation, A.-R.H. and H.-W.R.; writingreview and editing, A.-R.H., M.-J.H., K.-B.K. and H.-W.R.; visualization, B.N., H.-J.J., M.-J.H., S.-H.K. and H.-W.R.; supervision, A.-R.H. and H.-W.R.; project administration, A.-R.H., J.-B.K. and H.-W.R.; funding acquisition, J.-B.K. and H.-W.R. All authors have read and agreed to the published version of the manuscript.

Funding: This research was funded by the Korea Atomic Energy Research Institute (KAERI), grant number 523310-21 and the KRIBB Research Initiative Program funded by the Ministry of Science and ICT (MSIT).

Institutional Review Board Statement: Not applicable.

Informed Consent Statement: Not applicable.

Data Availability Statement: Not applicable.

Conflicts of Interest: The authors declare no conflict of interest.

\section{References}

1. Lam, Y.; Ng, T.B.; Yao, R.M.; Shi, J.; Xu, K.; Sze, S.; Zhang, K.Y. Evaluation of chemical constituents and important mechanism of pharmacological biology in Dendrobium plants. Evid. Based Complement. Alternat. Med. 2015, 2015, 841752. [CrossRef] [PubMed]

2. Gu, C.; Zhang, X.; Wu, L.; Jiang, X.; Huang, L. Quality evaluation of Dendrobium based on ultra-performance liquid chromatography (UPLC) and chemometrics. J. Appl. Pharm. Sci. 2017, 7, 17-23. [CrossRef]

3. Ng, T.B.; Liu, J.; Wong, J.H.; Ye, X.; Sze, S.C.W.; Tong, Y.; Zhang, K.Y. Review of research on Dendrobium, a prized folk medicine. Appl. Microbiol. Biot. 2012, 93, 1795-1803. [CrossRef] [PubMed]

4. $\quad$ Li, L.-S.; Lu, Y.-L.; Nie, J.; Xu, Y.-Y.; Zhang, W.; Yang, W.-J.; Gong, Q.-H.; Lu, Y.-F.; Lu, Y.; Shi, J.-S. Dendrobium nobile Lindl alkaloid, a novel autophagy inducer, protects against axonal degeneration induced by A $\beta 25-35$ in hippocampus neurons in vitro. CNS Neurosci. Ther 2017, 23, 329-340. [CrossRef]

5. Wang, Q.; Gong, Q.; Wu, Q.; Shi, J. Neuroprotective effects of Dendrobium alkaloids on rat cortical neurons injured by oxygenglucose deprivation and reperfusion. Phytomedicine 2010, 17, 108-115. [CrossRef] [PubMed]

6. Meng, C.-W.; He, Y.-L.; Peng, C.; Ding, X.-J.; Guo, L.; Xiong, L. Picrotoxane sesquiterpenoids from the stems of Dendrobium nobile and their absolute configurations and angiogenesis effect. Fitoterapia 2017, 121, 206-211. [CrossRef]

7. Morita, H.; Fujiwara, M.; Yoshida, N.; Kobayashi, J. New picrotoxinin-type and dendrobine-type sesquiterpenoids from Dendrobium snowflake 'Red Star'. Tetrahedron 2000, 56, 5801-5805. [CrossRef]

8. Yang, L.; Zhang, C.; Yang, H.; Zhang, M.; Wang, Z.; Xu, L. Two new alkaloids from Dendrobium chrysanthum. Heterocycles-Sendai Inst. Heterocycl. Chem. 2005, 65, 633-636.

9. Liu, G.-Y.; Tan, L.; Cheng, L.; Ding, L.-S.; Zhou, Y.; Deng, Y.; He, Y.-Q.; Guo, D.-L.; Xiao, S.-J. Dendrobine-type alkaloids and bibenzyl derivatives from Dendrobium findlayanum. Fitoterapia 2020, 142, 104497. [CrossRef] 
10. Song, T.-H.; Chen, X.-X.; Lee, C.K.-F.; Sze, S.C.-W.; Feng, Y.-B.; Yang, Z.-J.; Chen, H.-Y.; Li, S.-T.; Zhang, L.-Y.; Wei, G. Dendrobine targeting JNK stress signaling to sensitize chemotoxicity of cisplatin against non-small cell lung cancer cells in vitro and in vivo. Phytomedicine 2019, 53, 18-27. [CrossRef]

11. Charoenrungruang, S.; Chanvorachote, P.; Sritularak, B.; Pongrakhananon, V. Gigantol, a bibenzyl from Dendrobium draconis, inhibits the migratory behavior of non-small cell lung cancer cells. J. Nat. Prod. 2014, 77, 1359-1366. [CrossRef]

12. Bhummaphan, N.; Pongrakhananon, V.; Sritularak, B.; Chanvorachote, P. Cancer stem cell-suppressing activity of chrysotoxine, a bibenzyl from Dendrobium pulchellum. J. Pharmacol. Exp. Ther. 2018, 364, 332-346. [CrossRef]

13. Pinkhien, T.; Petpiroon, N.; Sritularak, B.; Chanvorachote, P. Batatasin III inhibits migration of human lung cancer cells by suppressing epithelial to mesenchymal transition and FAK-AKT signals. Anticancer Res. 2017, 37, 6281-6289.

14. Chanvorachote, P.; Kowitdamrong, A.; Ruanghirun, T.; Sritularak, B.; Mungmee, C.; Likhitwitayawuid, K. Anti-metastatic activities of bibenzyls from Dendrobium pulchellum. Nat. Prod. Commun. 2013, 8, 1934578X1300800127. [CrossRef]

15. Pai, H.-C.; Chang, L.-H.; Peng, C.-Y.; Chang, Y.-L.; Chen, C.-C.; Shen, C.-C.; Teng, C.-M.; Pan, S.-L. Moscatilin inhibits migration and metastasis of human breast cancer MDA-MB-231 cells through inhibition of Akt and Twist signaling pathway. J. Mol. Med. 2013, 91, 347-356. [CrossRef]

16. Gong, Y.-Q.; Fan, Y.; Wu, D.-Z.; Yang, H.; Hu, Z.-B.; Wang, Z.-T. In vivo and in vitro evaluation of erianin, a novel anti-angiogenic agent. Eur. J. Cancer. 2004, 40, 1554-1565. [CrossRef]

17. Lee, E.; Han, A.-R.; Nam, B.; Kim, Y.-R.; Jin, C.H.; Kim, J.-B.; Eun, Y.-G.; Jung, C.-H. Moscatilin induces apoptosis in human head and neck squamous cell carcinoma cells via JNK signaling pathway. Molecules. 2020, 25, 901. [CrossRef]

18. Zhang, X.; Xu, J.-K.; Wang, J.; Wang, N.-L.; Kurihara, H.; Kitanaka, S.; Yao, X.-S. Bioactive bibenzyl derivatives and fluorenones from Dendrobium nobile. J. Nat. Prod. 2007, 70, 24-28. [CrossRef]

19. Zhou, X.-M.; Zheng, C.-J.; Gan, L.-S.; Chen, G.-Y.; Zhang, X.-P.; Song, X.-P.; Li, G.-N.; Sun, C.-G. Bioactive phenanthrene and bibenzyl derivatives from the stems of Dendrobium nobile. J. Nat. Prod. 2016, 79, 1791-1797. [CrossRef]

20. Yang, D.; Liu, L.-Y.; Cheng, Z.-Q.; Xu, F.-Q.; Fan, W.-W.; Zi, C.-T.; Dong, F.-W.; Zhou, J.; Ding, Z.-T.; Hu, J.-M. Five new phenolic compounds from Dendrobium aphyllum. Fitoterapia 2015, 100, 11-18. [CrossRef]

21. Zhang, X.; Xu, J.-K.; Wang, N.-L.; Kurihara, H.; Yao, X. Antioxidant phenanthrenes and lignans from Dendrobium nobile. J. Chin. Pharm. Sci. 2008, 17, 314-318.

22. Kim, J.H.; Oh, S.-Y.; Han, S.-B.; Uddin, G.M.; Kim, C.Y.; Lee, J.K. Anti-inflammatory effects of Dendrobium nobile derived phenanthrenes in LPS-stimulated murine macrophages. Arch. Pharmacal Res. 2015, 38, 1117-1126. [CrossRef] [PubMed]

23. Hwang, J.S.; Lee, S.A.; Hong, S.S.; Han, X.H.; Lee, C.; Kang, S.J.; Lee, D.; Kim, Y.; Hong, J.T.; Lee, M.K. Phenanthrenes from Dendrobium nobile and their inhibition of the LPS-induced production of nitric oxide in macrophage RAW 264.7 cells. Bioorg. Med. Chem. Lett. 2010, 20, 3785-3787. [CrossRef] [PubMed]

24. Ito, M.; Matsuzaki, K.; Wang, J.; Daikonya, A.; Wang, N.-L.; Yao, X.-S.; Kitanaka, S. New phenanthrenes and stilbenes from Dendrobium loddigesii. Chem. Pharm. Bull. 2010, 58, 628-633. [CrossRef]

25. Bhummaphan, N.; Petpiroon, N.; Prakhongcheep, O.; Sritularak, B.; Chanvorachote, P. Lusianthridin targeting of lung cancer stem cells via Src-STAT3 suppression. Phytomedicine 2019, 62, 152932. [CrossRef]

26. Yang, H.; Sung, S.H.; Kim, Y.C. Antifibrotic phenanthrenes of Dendrobium nobile stems. J. Nat. Prod. 2007, 70, 1925-1929. [CrossRef]

27. Wattanathamsan, O.; Treesuwan, S.; Sritularak, B.; Pongrakhananon, V. Cypripedin, a phenanthrenequinone from Dendrobium densiflorum, sensitizes non-small cell lung cancer H460 cells to cisplatin-mediated apoptosis. J. Nat. Med. 2018, 72, 503-513. [CrossRef]

28. Zhao, G.-Y.; Deng, B.-W.; Zhang, C.-Y.; Cui, Y.-D.; Bi, J.-Y.; Zhang, G.-G. New phenanthrene and 9, 10-dihydrophenanthrene derivatives from the stems of Dendrobium officinale with their cytotoxic activities. J. Nat. Med. 2018, 72, 246-251. [CrossRef]

29. Chen, X.-J.; Mei, W.-L.; Zuo, W.-J.; Xeng, J.-B.; Guo, Z.-K.; Song, X.-Q.; Dai, H.-F. A new antibacterial phenanthrenequinone from Dendrobium sinense. J. Asian Nat. Prod. Res. 2013, 15, 67-70. [CrossRef]

30. Zhang, G.-N.; Zhong, L.-Y.; Bligh, S.A.; Guo, Y.-L.; Zhang, C.-F.; Zhang, M.; Wang, Z.-T.; Xu, L.-S. Bi-bicyclic and bi-tricyclic compounds from Dendrobium thyrsiflorum. Phytochemistry 2005, 66, 1113-1120. [CrossRef]

31. Kyokong, N.; Muangnoi, C.; Thaweesest, W.; Kongkatitham, V.; Likhitwitayawuid, K.; Rojsitthisak, P.; Sritularak, B. A new phenanthrene dimer from Dendrobium palpebrae. J. Asian Nat. Prod. Res. 2019, 21, 391-397. [CrossRef]

32. Zhang, X.; Liu, H.-W.; Gao, H.; Han, H.-Y.; Wang, N.-L.; Wu, H.-M.; Yao, X.-S.; Wang, Z. Nine new sesquiterpenes from Dendrobium nobile. Helv. Chim. Acta 2007, 90, 2386-2394. [CrossRef]

33. Zhao, W.; Ye, Q.; Dai, J.; Martin, M.-T.; Zhu, J. Allo-aromadendrane-and picrotoxane-type sesquiterpenes from Dendrobium moniliforme. Planta Med. 2003, 69, 1136-1140.

34. Park, B.-Y.; Oh, S.-R.; Ahn, K.-S.; Kwon, O.-K.; Lee, H.-K. (-)-Syringaresinol inhibits proliferation of human promyelocytic HL-60 leukemia cells via G1 arrest and apoptosis. Int. Immunopharmacol. 2008, 8, 967-973. [CrossRef]

35. Zhou, C.; Xie, Z.; Lei, Z.; Huang, Y.; Wei, G. Simultaneous identification and determination of flavonoids in Dendrobium officinale. Chem. Cent. J. 2018, 12, 40. [CrossRef]

36. Poudel, M.R.; Chand, M.B.; Karki, N.; Pant, B. Antioxidant activity and total phenolic and flavonoid contents of Dendrobium amoenum Wall. ex Lindl. Bot. Orient. J. Plant. Sci. 2015, 9, 20-26. [CrossRef]

37. Zhao, Y.; Son, Y.-O.; Kim, S.-S.; Jang, Y.-S.; Lee, J.-C. Antioxidant and anti-hyperglycemic activity of polysaccharide isolated from Dendrobium chrysotoxum Lindl. J. Biochem. Mol. Biol. 2007, 40, 670-677. [CrossRef] 
38. Liang, J.; Wu, Y.; Yuan, H.; Yang, Y.; Xiong, Q.; Liang, C.; Li, Z.; Li, C.; Zhang, G.; Lai, X. Dendrobium officinale polysaccharides attenuate learning and memory disabilities via anti-oxidant and anti-inflammatory actions. Int. J. Biol. Macromol. 2019, 126, 414-426. [CrossRef]

39. Xia, L.; Liu, X.; Guo, H.; Zhang, H.; Zhu, J.; Ren, F. Partial characterization and immunomodulatory activity of polysaccharides from the stem of Dendrobium officinale (Tiepishihu) in vitro. J. Funct. Foods 2012, 4, 294-301. [CrossRef]

40. Nam, B.; Ryu, S.M.; Lee, D.; Jung, C.-H.; Jin, C.H.; Kim, J.-B.; Lee, I.-S.; Han, A.-R. Identification of two new phenanthrenes from Dendrobii Herba and their cytotoxicity towards human hypopharynx squamous carcinoma cell (FaDu). Molecules 2019, 24, 2339. [CrossRef]

41. Ali, H.; Ghori, Z.; Sheikh, S.; Gul, A. Effects of gamma radiation on crop production. In Crop Production and Global Environmental Issues; Hakeem, K., Ed.; Springer: Cham, Switzerland, 2016; pp. 27-78.

42. Jankowicz-Cieslak, J.; Mba, C.; Till, B.J. Mutagenesis for crop breeding and functional genomics. In Biotechnologies for Plant Mutation Breeding; Jankowicz-Cieslak, J., Tai, T., Kumlehn, J., Till, B., Eds.; Springer: Cham, Switzerland, 2017 ; pp. 3-18.

43. Jo, Y.D.; Kim, Y.-S.; Ryu, J.; Choi, H.-I.; Kim, S.W.; Kang, H.S.; Ahn, J.-W.; Kim, J.-B.; Kang, S.-Y.; Kim, S.H. Deletion of carotenoid cleavage dioxygenase $4 \mathrm{a}(\mathrm{CmCCD} 4 \mathrm{a})$ and global up-regulation of plastid protein-coding genes in a mutant chrysanthemum cultivar producing yellow petals. Sci. Hortic. 2016, 212, 49-59. [CrossRef]

44. Hong, M.J.; Kim, D.Y.; Nam, B.; Ahn, J.-W.; Kwon, S.-J.; Seo, Y.W.; Kim, J.-B. Characterization of novel mutants of hexaploid wheat (Triticum aestivum L.) with various depths of purple grain color and antioxidant capacity. J. Sci. Food Agric. 2019, 99 , 55-63. [CrossRef] [PubMed]

45. Yang, J.; Han, X.; Wang, H.-Y.; Yang, J.; Kuang, Y.; Ji, K.-Y.; Yang, Y.; Pang, K.; Yang, S.-Z.; Qin, J.-X.; et al. Comparison of metabolomics of Dendrobium officinale in different habitats by UPLC-Q-TOF-MS. Biochem. Syst. Ecol. 2020, 89, 104007. [CrossRef]

46. Wang, Y.-H.; Avula, B.; Abe, N.; Wei, F.; Wang, M.; Ma, S.-C.; Ali, Z.; Elsohly, M.A.; Khan, I.A. Tandem Mass Spectrometry for Structural Identification of Sesquiterpene Alkaloids from the Stems of Dendrobium nobile Using LC-QToF. Planta Med. 2016, 82, 662-670. [CrossRef]

47. Tao, Y.; Cai, H.; Li, W.; Cai, B. Ultrafiltration coupled with high-performance liquid chromatography and quadrupole-time-offlight mass spectrometry for screening lipase binders from different extracts of Dendrobium officinale. Anal. Bioanal. Chem. 2015, 407, 6081-6093. [CrossRef]

48. Zha, X.-Q.; Luo, J.-P.; Wei, P. Identification and classification of Dendrobium candidum species by fingerprint technology with capillary electrophoresis. S. Afr. J. Bot. 2009, 75, 276-282. [CrossRef]

49. Li, Y.; Wang, C.-L.; Guo, S.-X.; Yang, J.-S.; Xiao, P.-G. Two new compounds from Dendrobium candidum. Chem. Pharm. Bull. 2008, 56, 1477-1479. [CrossRef]

50. Xu, Y.-Y.; Wang, L.-Y.; Huang, B.; Xie, X.-L.; Wu, Q.; Shi, J.-S. Comparison of contents of polysaccharides and alkaloids in Dendrobium from different harvest time. Chin. Pharm. J. 2014, 29, 288-291.

51. Chen, H.; Li, X.; Xu, Y.; Lo, K.; Zheng, H.; Hu, H.; Wang, J.; Lin, Y. Study on the polar extracts of Dendrobium nobile, D. officinale, D. loddigesii, and Flickingeria fimbriata: Metabolite identification, content evaluation, and bioactivity assay. Molecules 2018, $23,1185$. [CrossRef]

52. Song, J.I.; Kang, Y.J.; Yong, H.; Kim, Y.C.; Moon, A. Denbinobin, a phenanthrene from Dendrobium nobile, inhibits invasion and induces apoptosis in SNU-484 human gastric cancer cells. Oncol. Rep. 2012, 27, 813-818.

53. Zhang, Y.; Zhang, Q.; Xin, W.; Liu, N.; Zhang, H. Nudol, a phenanthrene derivative from Dendrobium nobile, induces cell cycle arrest and apoptosis and inhibits migration in osteosarcoma cells. Drug Des Dev. Ther. 2019, 13, 2591-2601. [CrossRef]

54. Sun, J.; Guo, Y.; Fu, X.; Wang, Y.; Liu, Y.; Huo, B.; Sheng, J.; Hu, X. Dendrobium candidum inhibits MCF-7 cells proliferation by inducing cell cycle arrest at G2/M phase and regulating key biomarkers. OncoTargets Ther. 2016, 9, 21-30.

55. Rahman, S.; Haq, F.U.; Ali, A.; Khan, M.N.; Shah, S.M.Z.; Adhikhari, A.; El-Seedi, H.R.; Musharraf, S.G. Combining untargeted and targeted metabolomics approaches for the standardization of polyherbal formulations through UPLC-MS/MS. Metabolomics 2019, 15, 1-11. [CrossRef]

56. Liu, M.; Liu, Q.; Liu, Y.-L.; Hou, C.-Y.; Mabry, T.J. An acylated flavone C-glycoside from Glycyrrhiza eurycarpa. Phytochemistry 1994, 36, 1089-1090. [CrossRef]

57. König, G.M.; Wright, A.D.; Keller, W.J.; Judd, R.L.; Bates, S.; Day, C. Hypoglycaemic activity of an HMG-containing flavonoid glucoside, chamaemeloside, from Chamaemelum nobile. Planta Med. 1998, 64, 612-614. [CrossRef]

58. Smiljkovic, M.; Stanisavljevic, D.; Stojkovic, D.; Petrovic, I.; Vicentic, J.M.; Popovic, J.; Grdadolnik, S.G.; Markovic, D.; SankovicBabice, S.; Glamoclija, J.; et al. Apigenin-7-O-glucoside versus apigenin: Insight into the modes of anticandidal and cytotoxic actions. EXCLI J. 2017, 16, 795-807.

59. Czemplik, M.; Mierziak, J.; Szopa, J.; Kulma, A. Flavonoid C-glucosides derived from Flax straw extracts reduce human breast cancer cell growth in vitro and induce apoptosis. Front. Pharmacol. 2016, 31, 282. [CrossRef] [PubMed] 